\title{
The impact of persistent milk consumption in the pathogenesis of type 2 diabetes mellitus
}

\author{
Bodo C. Melnik ${ }^{1}$ and Gerd Schmitz ${ }^{2}$ \\ ${ }^{1}$ Department of Dermatology, Environmental Medicine and Health Theory, University of \\ Osnabrück, Osnabrück, Germany; ${ }^{2}$ Institute for Clinical Chemistry and Laboratory Medicine, \\ University Hospital Regensburg, Regensburg, Germany
}

Corresponding author: Bodo C. Melnik, MD, Department of Dermatology, Environmental Medicine and Health Theory, University of Osnabruck, Germany

Submission Date: July 26 ${ }^{\text {th }}$, 2019. Acceptance Date: October $28^{\text {th }}$, 2019; Publication Date: October $30^{\text {th }}, 2019$

Citation: Melnik BC, Schmitz G. The impact of persistent milk consumption in the pathogenesis of type 2 diabetes mellitus. Functional Foods in Health and Disease 2019; 9(10): 629-647 DOI: https://doi.org/10.31989/ffhd.v9i10.654

\begin{abstract}
Background: Milk and sugar are excessively consumed in a Western diet. There is increasing epidemiological evidence that the intake of unfermented pasteurized cow's milk is associated with an increased risk of type 2 diabetes mellitus (T2D). It is the intention of this review to provide translational biochemical evidence for milk's diabetogenic mode of action. Milk proteins provide the highest amounts of branched-chain amino acids (BCAAs) and thus contribute to total BCAA intake, which enhances BCAA plasma levels associated with increased risk of T2D. The consumption of pasteurized milk raises plasma levels of miRNA-29b, which is a diabetogenic miRNA promoting insulin resistance (IR). miRNA29b inhibits the activity of branched-chain $\alpha$ keta acid dehydrogenase, the rate limiting enzyme of BCAA catabolism, which is impaired in patients with IR and T2D. Milk consumption stimulates mTORC1 activity and increases insulin synthesis. $\beta$-cell mTORC1 is overactivated in T2D patients resulting in impaired autophagy which enhances endoplasmic reticulum (ER) stress associated with a greater risk of early $\beta$-cell apoptosis, the pathogenic hallmark of T2D. Chronic insulinotropic action of milk-derived BCAAs, IRpromoting mTORC1 overactivity, and miRNA-29b signaling combined with excessive glucosemediated insulin secretion overburden $\beta$-cell insulin homeostasis. Epidemiological and translational evidence identifies continued milk intake as a promoter of $\mathrm{T} 2 \mathrm{D}$, the most common metabolic disease of Western civilization.
\end{abstract}

Keywords: Branched-chain amino acids, branched-chain $\alpha$-keto acid dehydrogenase, diabetes mellitus type 2, insulin resistance, milk, miRNA-29b, mechanistic target of rapamycin complex 1. 


\section{INTRODUCTION}

Type 2 diabetes mellitus (T2D), a worldwide epidemic, is a progressive metabolic disease initially developing insulin resistance (IR) with enhanced pancreatic $\beta$-islet activity, hyperinsulinemia, enhanced endoplasmic reticulum (ER) stress, and subsequent $\beta$-cell apoptosis with failure of insulin secretion. As the disease progresses, pancreatic $\beta$-cells are overstressed and fail to compensate for the IR. T2D is closely related to Western diets providing excessive amounts of sugar and saturated fats. Glucotoxicity and lipotoxicity are thus believed to play a key role in the pathogenesis of T2D. However, milk is another abundant component of a Western diet, which is the focus of this review. In 2017, a per capita milk consumption in the United States of $65.2 \mathrm{~L}$ (16.5 US gal) has been reported [1], which underlines the presence of cow milk as a substantial factor of the dietary exposome. Milk exerts high insulinotropic effects [2]. A large and similar dissociation of the glycemic index and insulinemic index exists for both whole milk $(42 \pm 5$ and $148 \pm 14)$ and skim milk (37 \pm 9 and $140 \pm 13$ ), respectively [3]. These observations clearly indicate that milk consumption has a stimulatory effect on insulin secretion and affects glucose homeostasis. Evidence provided by prospective cohort studies, which are frequently supported by the dairy industry, and limited randomized controlled trials (RCTs) suggests that total dairy consumption has a neutral or moderately beneficial effect on type 2 diabetes (T2D) risk [4]. In contrast, accumulating epidemiological evidence supports a relationship between the intake of non-fermented whole and skim milk and T2D [5-9]. It is the intention of this review to present epidemiologic and translational evidence underlining a key role of persistent cow milk consumption in the pathogenesis of T2D.

\section{Epidemiological evidence}

In 2005, Hoppe and et al. [5] observed that the intake of skim milk (53 g milk protein) but not lowfat meat (53 g protein) induced IR in 8-yr old Danish boys. A Mendelian randomization study in 97,811 Danish individuals showed that especially the intake of fat-free milk is associated with a higher risk for T2D [6]. The Physicians' Health study of U.S. male physicians $(\mathrm{n}=21,660)$ reported a significant increase of diabetes risk from $1.7 \%$ to $2.6 \%$ by increasing the servings of whole milk from $\leq 1$ /week to $\geq 2$ /week and from $1.6 \%$ to $2.3 \%$ by increasing the servings of skim/low-fat milk from $\leq 1 /$ week to $\geq 2$ /week, respectively [7]. A nested case-cohort within 8 European countries of the European Prospective Investigation into Cancer and Nutrition (EPIC) Study ( $n=340,234)$ analyzed the amount and type of dairy product intake and incident T2D and demonstrated an increased risk for T2D by milk consumption in 5 of 8 countries [8]. The Dutch Lifeline Cohort Study $(\mathrm{n}=112,086)$ investigated the association of non-fermented milk products, milk, and fermented milk products on participants with prediabetes (defined as fasting plasma glucose between 5.6 and $6.9 \mathrm{mmol} / \mathrm{l}$ or $\mathrm{HbA} 1 \mathrm{c}$ of 5.7-6.4\%) and newly diagnosed T2D (defined as fasting plasma glucose $>7.0 \mathrm{mmol} / \mathrm{l}$ or $\mathrm{HbA} 1 \mathrm{c}>6.5 \%$ ) [9]. A positive association between fullfat milk consumption (150 g/day) as well as non-fermented dairy products with prediabetes has been shown. Notably, a significant positive association between milk (serving $150 \mathrm{~g} / \mathrm{day}$ ) and predominantly skim milk consumption (150 g/day) with T2D has been observed [9]. Hruby et al. [10] investigated the type of dairy intake of participants of the Framingham Heart Study Offspring Cohort and found an association of total, low-fat, skim milk, whole milk, and yoghurt intake with incident prediabetes in middle-aged U.S. adults depending on the preexisting glycemic status. 
Of all animal protein sources, milk proteins (whey proteins and caseins) provide highest amounts of essential branched-chain amino acids (BCAAs). In comparison to beef proteins, milk proteins provide five times higher amounts of leucine, isoleucine, and valine ( $\mathrm{g} / 100 \mathrm{~g}$ amino acids), respectively (Table 1) [11-13]. Cumulative consumption of BCAAs has been associated with increased risk of T2D among participants from three prospective cohorts: Nurses' Health Study (NHS; followed from 1980 to 2012), NHS II (followed from 1991 to 2011), and Health Professionals Follow-up Study (HPFS; followed from 1986 to 2010) [14]. The Hong Kong Dietary Survey correlated increased dairy and meat protein intake with a 39\% increased risk of T2D during the transition of a Chinese population from their traditional diet to Western style diet [15]. Fasting serum insulin levels of subsistence dairy-free horticulturalists in the tropical island of Kitava (Trobriand Islands, Papua New Guinea) were 50\% lower compared to milk-consuming Swedish controls from the Northern Sweden WHO Monitoring Trends and Determinants in Cardiovascular Diseases (MONICA) cohort [16]. Paleolithic-like diets that exclude milk and dairy products as well as refined sugar have beneficial effects in the prevention and treatment of IR and T2D [1720].

\section{Hyperactivation of mTORC1 in type 2 diabetes}

The growth factor and BCAA-sensitive kinase mTORC1 (mechanistic target of rapamycin complex 1) plays a key role in metabolic homeostasis and the regulation of autophagy [21-23]. Overactivated mTORC1 signaling of peripheral cells of the body (liver, adipose tissue, skeletal muscle) promotes S6K1-mediated IR by negative phosphorylation of insulin receptor substrate 1 (IRS-1) [24-26]. IR enhances the metabolic demand and burden of $\beta$-cells by increasing insulin synthesis and secretion [27].

Under nutrient-rich conditions, mTORC1 orchestrates cell growth by stimulating biosynthetic pathways, including synthesis of proteins, insulin, lipids, and nucleotides, and by inhibiting cellular catabolism through repression of autophagy pathways [28, 29]. Autophagy is necessary to maintain the structure, mass, and function of pancreatic $\beta$-cells. Impaired autophagy by overactivated mTORC1 enhances ER stress associated with an increased risk of $\beta$-cell apoptosis [30]. Overactivation of mTORC1 has been linked to the pathogenesis of obesity, IR, and T2D [3134]. Recent findings uncover mTORC1's importance as an emerging significant player in the development and progression of $\beta$-cell failure in T2D and suggest that mTORC1 may act as a "double-edged sword" in the regulation of $\beta$-cell mass and function in response to metabolic stress such as nutrient overload and IR [35]. Hyperactivation of mTORC1 has been observed in pancreatic islets from animal models of T2D and human islets from patients with T2D, which leads to $\beta$-cell loss [36]. Elevated mTORC1 activation is a striking pathogenic hallmark of islets in T2D, contributing to impaired $\beta$-cell function and survival in the presence of metabolic stress [36, 37]. It has been shown that chronic over-activation of mTORC1 in $\beta$-islets from prediabetic patients makes $\beta$-cells more prone to trigger apoptosis upon several cellular stressors, allowing the progression from prediabetes to T2D [38]. Intriguingly, Jaafar et al. [39] recently demonstrated in mice that post-weaning $\beta$-cell maturation is associated with a switch from mTORC1 activation to activation of 5'-adenosine monophosphate-activated protein kinase (AMPK). The reverse direction from AMPK to mTORC1 activation has been observed in T2D dysfunctional $\beta$-cells [39]. 


\section{Milk: mammals mTORC1-driver for the postnatal growth period}

Milk is a specialized nutrient and signaling system of mammals that is physiologically restricted to operate during the lactation period for adequate promotion of mTORC1-dependent postnatal anabolism and growth [40, 41]. Milk consumption activates mTORC1 by enhancing the endogenous synthesis of insulin and insulin-like growth factor-1 (IGF-1) and by transfer of mTORC1-activating amino acids [40,41]. Milk protein contains abundant quantities of leucine, isoleucine, valine, arginine, glutamine, and methionine as critical stimulators of mTORC1 [42-49] (Table 1).

\section{Insulinotropic effect of milk}

Milk protein derived BCAAs induce postprandial hyperinsulinemia explaining the high insulinemic index of milk, which is three times higher than its glycemic index [2, 50]. This milk protein-specific effect is mediated by fast intestinal hydrolysis of whey proteins and systemic absorption of released insulinotropic amino acids [51, 52], which stimulate insulin secretion of pancreatic $\beta$-cells [53]. About $23 \%$ of amino acids of whey protein have insulinotropic effects [54, 55]. Furthermore, whey increases the gastric emptying rate, stimulates the intestinal release of the incretin hormones glucose-dependent insulinotropic peptide (GIP) and glucagon-like polypeptide1 (GLP-1), and functions as an inhibitor of dipeptidyl peptidase IV [56-59]. Thus, milk-derived BCAAs and incretin signaling enhances insulin synthesis and secretion and thereby increases the metabolic burden of $\beta$-cells. Moreover, insulin enhances peripheral activation of AKT-mTORC1signaling increasing the risk of peripheral IR (Fig. 1) [60]. In contrast to milk signaling, recent treatment strategies for T2D are targeted towards reducing the systemic metabolic burden, rather than demanding greater insulin production from an already overstressed $\beta$-cell [61] (Fig. 1).

\section{Insulin-like growth factor 1}

Milk consumption increases the synthesis and plasma levels of IGF-1 [62-64]. Daily intake of 710 $\mathrm{ml}$ of ultraheat-treated milk for 1 month to prepubertal school children, who were not used to ingesting milk, resulted in a significant increase of growth hormone (GH) and IGF-1 pointing to an impact of milk consumption on the somatotropic axis [65]. Tryptophan and methionine, abundant amino acids of the casein fraction of milk (Table 1), promote hepatic IGF-1 synthesis [65-69]. Furthermore, cow milk contains bovine IGF-1, which is identical to human IGF-1 [7072]. In synergy with insulin, IGF-1 activates the AKT-mTORC1 pathway (Fig. 1) [41, 43].

Milk consumption and increased IGF-1 serum levels are associated with increased linear growth and body mass index [73, 74]. Remarkably, untreated individuals with Laron syndrome due to defective GH receptor signaling and congenital IGF-1 deficiency have less IR and lower incidence of T2D than their relatives [75-77]. In fact, an association of free IGF-1 serum levels and T2D has been reported in the Nurses' Health Study [78], whereas a nested case-cohort study within the EPIC-Potsdam Study found no association between total IGF-1 serum concentrations with risk of T2D [79]. A longitudinal study in a multiracial cohort supported a correlation between increased IGF-1 and gestational diabetes mellitus [80]. Notably, milk consumption during pregnancy, which is generally recommended by obstetricians and gynecologists [81], may increase maternal IGF-1 levels and infant's birth weight [82], a risk factor for obesity and T2D in later life [83]. 


\section{mTORC1-activating amino acids}

Milk protein is the richest animal source of BCAAs (Table 1). Caseins are highly enriched in methionine. Whey proteins contain highest amounts of leucine [11, 12]. Milk protein in comparison to beef $(4.8 \mathrm{~g} / 100 \mathrm{~g})$ contains higher amounts of glutamine $(8.1 \mathrm{~g} / 100 \mathrm{~g}$ protein) [13]. Glutamine in synergy with leucine activates mTORC1 [43]. Leucine, methionine, arginine, and glutamine are detected by cellular amino acid sensors that subsequently activate mTORC1 [4448]. Leucine is regarded as the primary BCAA activating mTORC1 [41]. Apparently, the composition of milk amino acids has been precisely adapted during mammalian evolution to provide optimized input signals for mTORC1 activation of the milk recipient. In the lysosomal compartment, milk amino acids stimulate mTORC1 in a Rag GTPase-dependent and Rag-GTPaseindependent fashion [84-88] (Fig. 1). Amino acid-mediated activation of mTORC1 is further supported by growth factor signals, especially insulin and IGF-1, which, via AKT-mediated phosphorylation of tuberin (TSC2), activate the GPTase Rheb that finally activates mTORC1 [43, 49].

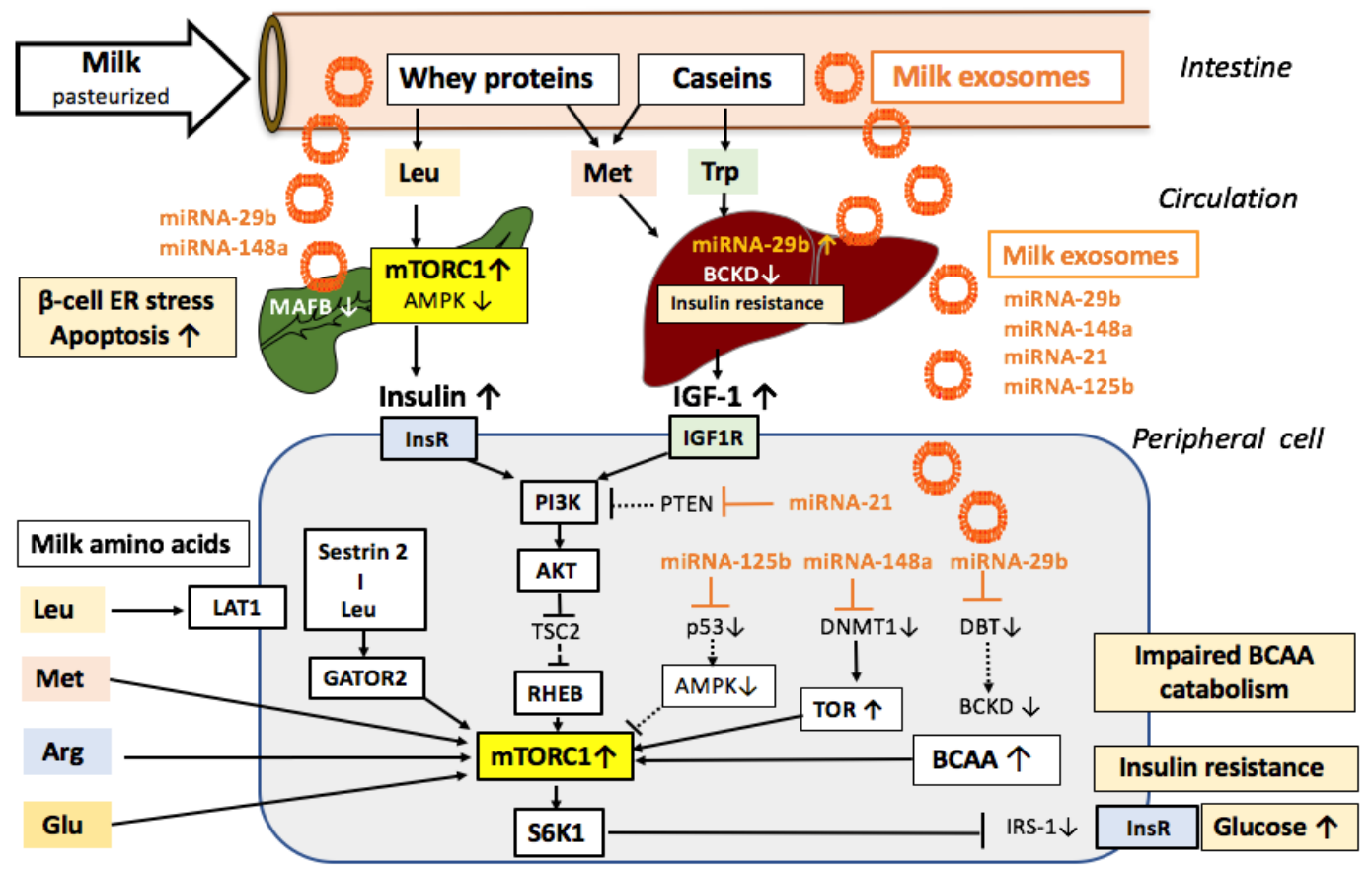

Figure 1: Working model of milk signaling in the pathogenesis of type 2 diabetes mellitus (T2D). Milk-derived amino acids (leucine, methionine, arginine, glutamine) enhance mechanistic target of rapamycin complex 1 (mTORC1) activity and insulin synthesis and secretion of pancreatic $\beta$-cells promoting $\beta$-cell growth during the breastfeeding period. However, chronic milk intake induces endoplasmic reticulum (ER) stress when mTORC1-overstimulation by milk signaling is not physiologically discontinued. Plasma levels of diabetogenic miRNA-29b rise six hours after consumption of pasteurized cow's milk and might reach the liver and peripheral tissues by exosomal miRNA transfer. miRNA-29b targets dihydrolipoamide branched-chain acyltransferase (DBT), the E2 core component of branched chain $\alpha$-ketoacid dehydrogenase (BCKD), reducing the catabolism of branchedchain amino acids (BCAAs), the metabolic signature of insulin resistance (IR) and T2D. miRNA-148a targets V-MAF musculoaponeurotic fibrosarcoma oncogene family, protein B (MAFB) and DNA methyltransferase 1 (DNMT1) involved in the regulation of $\beta$-cell differentiation and TOR expression. Milk miRNA-21 via targeting phosphatase and tensin homolog (PTEN) enhances mTORC1 signaling in accordance with milk miRNA-125b-mediated suppression of p53, a key negative regulator of mTORC1 and activator of AMPK. Persistent mTORC1 activation of peripheral cells stimulates S6K1-mediated negative phosphorylation of insulin receptor substrate-1 (IRS-1) promoting IR enhancing $\beta$-cell ER stress accelerating $\beta$-cell apoptosis, the metabolic hallmark of T2D. 
Table 1. Amino acid composition of milk proteins compared to animal and plant protein sources according to Souci et al. (12) and *Lenders et al. (13)

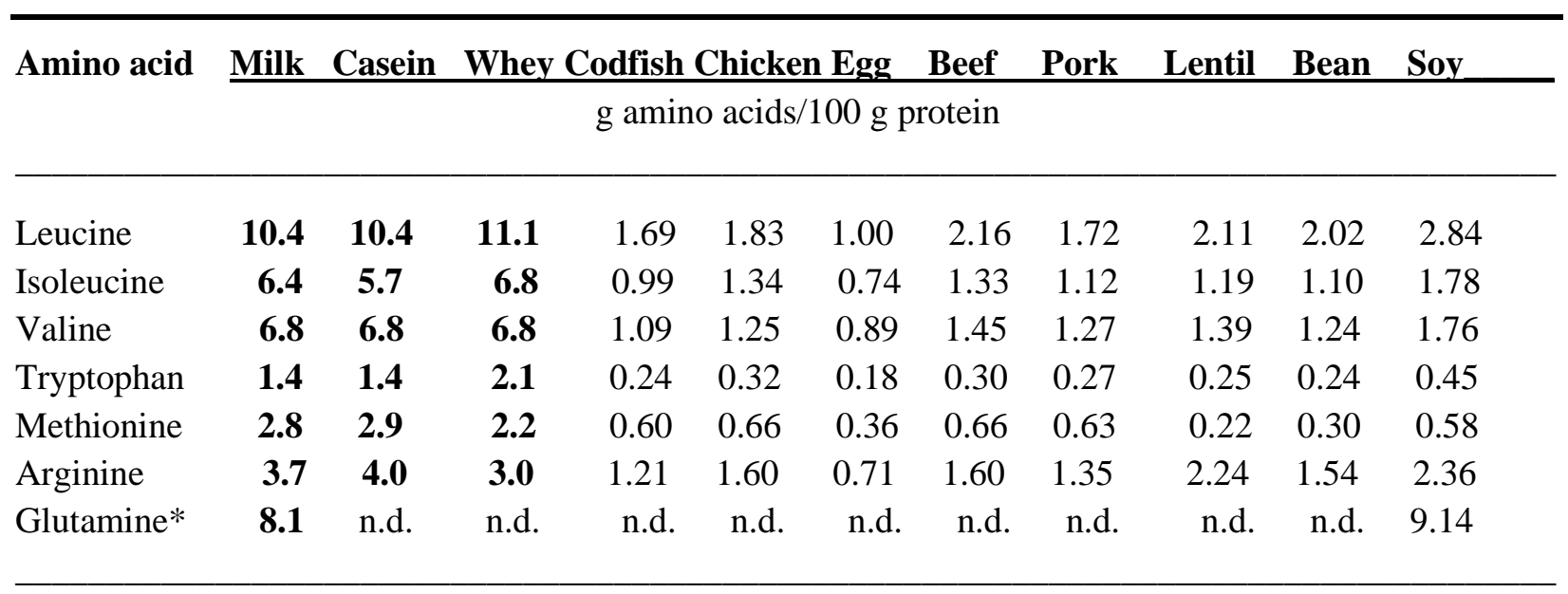

n.d. $=$ not determined

\section{Milk fatty acids and MFG-E8}

The predominant fatty acid of milk fat globule (MFG) triacylglycerols is palmitic acid. This saturated fatty acid is able to activate mTORC1 in the lysosomal compartment $[89,90]$. The MFG membrane protein EGF-factor 8 (MFG-E8), which constitutes over $80 \%$ of MFG membrane proteins, likewise activates PI3K/AKT/mTORC1 signaling [91].

Thus, milk provides multiple macronutrient components that exhibit signaling functions converging in the activation of mTORC1 of the milk recipient.

\section{Milk-derived miRNAs}

Fresh and pasteurized cow milk transfers bioactive gene-regulatory micro-ribonucleic acids (miRNAs), which are protected from intestinal degradation by secretion as membrane-coated extracellular vesicles (EVs) and exosomes [92-99]. It has recently been demonstrated that orally administered cow milk exosomes $(50-100 \mathrm{~nm})$ and their specific miRNAs are distributed into various organs of mice, especially the liver [100,101]. miRNAs bind to their specific target messenger RNAs (mRNAs) leading to attenuation or either complete suppression of gene expression [102, 103]. Cow milk contains more than 400 miRNAs. The predominant bovine miRNA, miRNA-148a, is identical with human miRNA-148a and survives pasteurization and is a major miRNA component of milk fat [104, 105]. miRNA-148a inhibits the expression of DNA methyltransferase 1 (DNMT1) [106, 107], which is involved in epigenetic regulation of the human genome [108-110]. Notably, further signature miRNAs of cow milk, miRNA-21 and miRNA-29b, indirectly target DNMT1 [106, 111]. Demethylation of the P2 promoter region of the IGF1 gene increases IGF-1 expression [112]. In addition, the promotor regions of the insulin (INS) and mTOR $(M T O R)$ genes are activated by demethylation [113,114]. miRNA-21 targets multiple tumor suppressor genes such as phosphatase and tensin homolog (PTEN) resulting in increased PI3KAKT-mTORC1 signaling [40, 115, 116]. miRNA-125b, miRNA-30d, and miRNA-25 are further miRNA components of cow milk that target p53, the guardian of the genome [108, 117-119], functioning as a key inhibitor of mTORC1 [120, 121]. Two p53 target genes, sestrin 1 and sestrin 2, activate AMPK, which phosphorylates and stimulates GAP activity of tuberin (TSC2), thereby 
inhibiting mTORC1 [122]. Thus, there is substantial evidence that milk-derived miRNAs augment mTORC1 signaling as important driver of postnatal $\beta$-cell growth during the neonatal period [123, 124].

The transcription factor MAFB increases the expression of MAFA, which is important to maintain pancreatic $\beta$-cell function in adults $[125,126]$. Notably, MAFB is a direct target of miRNA-148a [127]. miRNA-148a has been detected as a major miRNA component of bovine milk and milk fat as well as human MFGs [105, 128]. Notably, MAFA was lower in islets of mice provided milk fat [39]. Thus, persistent milk consumption in adults may maintain an immature $\beta$ cell phenotype with less MAFA expression and increased mTORC1 activation.

\section{Milk miRNA-29b and impaired BCAA catabolism}

Recent studies implicate a strong association between elevated plasma BCAAs and IR [32, 129138]. Moreover, Zhou et al. [139] identified a unique genetic link between obesity-associated IR and BCAA catabolic gene expression at the pathway level in human and mouse populations. In genetically obese (ob/ob) mice, rate-limiting branched-chain $\alpha$-keto acid (BCKA) dehydrogenase deficiency associated with BCAA and BCKA accumulation accompanied the systemic suppression of BCAA catabolic genes. Restoring BCAA catabolic flux with a pharmacological inhibitor of BCKA dehydrogenase kinase (BCKDK, a suppressor of BCKA dehydrogenase) reduced the abundance of BCAA and BCKA and markedly attenuated IR in ob/ob mice. Similar outcomes were achieved by reducing protein (and thus BCAA) intake, whereas increasing BCAA intake did the opposite. This corroborates the pathogenic roles of BCAAs and BCKAs in IR in ob/ob mice [139]. Like BCAAs, BCKAs also suppress insulin signaling via activation of mTORC1. In ob/ob mice and other rodent models of IR and T2D such as streptozotocin-injected mice, Zucker fatty rats, and UC Davis T2D rats, liver-specific insulin receptor knockout, hepatic miRNA-29b, is overexpressed $[140,141]$. The miRNA-29 family is among the most abundantly expressed miRNAs in the pancreas and liver. Overexpression of miRNA-29b has also been observed in the muscle, adipose tissue, and liver of diabetic Goto-Kakizaki rats [142]. Levels of miRNA-29a/b/c increased in islets of NOD mice during the phases preceding the manifestation of diabetes and in isolated mouse and human islets exposed to proinflammatory cytokines [143]. miRNA-29a and miRNA-29b contribute to pancreatic $\beta$-cell-specific silencing of monocarboxylate transporter 1 (MCT1) and may thus affect insulin release [144]. The miRNA-29 family dictates the balance between homeostatic and pathological glucose handling in diabetes and obesity [145]. Baran-Gale et al. [146] identified $10 \beta$-cell miRNA families as candidate regulatory hubs in a T2D gene network. The most significant candidate hub was miRNA-29, which regulates mRNA levels of several genes critically involved in $\beta$-cell functions and development of T2D. Remarkably, acute suppression of the miRNA-29 family in adult mice improved glycemic control [140].

More than $50 \%$ of bovine milk miRNA-29b was still detectable after pasteurization and homogenization of whole and $2 \%$ fat milk in comparison to raw milk, whereas one third of miRNA-29b was recovered in skim milk after these procedures [147]. Remarkably, consumption of commercial milk increased miRNA-29b plasma levels of healthy volunteers in a dosedependent manner [148]. Milk miRNA-29b also increased in peripheral blood monocytes after milk intake [148]. It is thus conceivable that milk exosome uptake is responsible for this effect $[100,101,110]$. Part of bovine milk exosome uptake is mediated by bovine immunoglobulin $\mathrm{G}$ 
(IgG), which binds to human neonatal Fc receptor (FcRn) [149] and is highly expressed in adult human liver and other human organs [150]. The mature sequences of human and bovine miRNA$29 \mathrm{~b}$ are identical (mirbase.org). Notably, Mersey et al. [151] demonstrated that miRNA-29b plays an important role in determining the total amount of BCKD present in the cell. miRNA-29b targets the mRNA for the dihydrolipoamide branched-chain acyltransferase (DBT) component of BCKD and prevents translation when bound. BCKD is composed of a core of 24 DBT (E2) subunits, which are critical for BCKD function [152]. Thus, milk miRNA-29b-mediated suppression of BCKD activity might impair BCAA catabolism [110, 153, 154], a key metabolic signature of IR and T2D [32, 129-138]. Milk miRNA-29b-mediated suppression of BCAA catabolism appears to be a protective mechanism preventing BCAA oxidation in order to provide sufficient quantities of BCAAs for postnatal synthesis of BCAA-dependent structural and functional proteins as well as BCAA-mTORC1-driven $\beta$-cell proliferation [153]. Physiologically, milk-mediated suppression of BCAA catabolism is terminated after the breastfeeding period in all mammals except Neolithic humans, who after widespread distribution of refrigeration technology in the 1950s, enhanced their intake of pasteurized milk and BCAA-rich milk products [32]. Before the era of the refrigerator, Neolithic humans predominantly consumed fermented milk and fermented dairy products such as yoghurt, in which exosome integrity and miRNA content is reduced due to bacterial fermentation [155]. Pasteurized milk in contrast to fermented milk provides both BCAAs and bioactive miRNA29b, which inhibits BCAA catabolism. Thus, pasteurized milk has the strongest diabetogenic effect by raising BCAA levels by transfer of BCAAs combined with an inhibitory activity on BCAA catabolism.

\section{DISCUSSION}

Milk is mammal's most sophisticated functional food to ensure abundant BCAA and exosomal miRNA transfer for adequate mTORC1 signaling required for $\beta$-cell growth and postnatal tissue maturation. In all mammalian species, except Neolithic humans, this signaling system is confined to the nursing period which substantially affects $\beta$-cell function and homeostasis. Recent evidence supports the view that mTORC1-dependent $\beta$-cell growth during the lactation period has to switch to AMPK-regulated $\beta$-cell function after weaning, when glucose signals are the primary stimulus of the $\beta$-cell for insulin secretion [39]. Continued exposure to milk and their miRNAs including IR-promoting miRNA-29b enhance BCAA and miRNA-driven overactivation of $\beta$-cell mTORC1. Persistently increased mTORC1 activation of $\beta$-cells reduces their capacity for autophagy enhancing chronic ER stress promoting early $\beta$-cell apoptosis, the major pathogenic event in T2D $[30,32,156]$. In fact, upregulation of amino acid transport in $\beta$-cells during ER stress with increased transfer of leucine and tryptophan involves responses leading to increased protein synthesis, which can be protective during acute stress but leads to apoptosis during chronic ER stress [156]. To improve $\beta$-cell metabolic health and to reduce somatic IR, the excessive and continued intake of BCAAs of animal proteins supplied by persistent consumption of milk, dairy products and meat needs to be reduced [137, 157-160]. Pasteurized milk, widely distributed by refrigeration technology since the 1950s, transfers diabetogenic miRNA-29b into the human food chain $[40,41,153]$. Milk consumption, especially in synergy with excessive glucose intake [3], is a typical and frequent in a Western diet and may accelerate the pathogenesis of T2D, which is in accordance with epidemiological evidence [6-10]. 
Based on epidemiological and translational evidence, we conclude that a restriction of BCAArich dairy proteins in conjunction with the elimination of milk-derived miRNAs may be a meaningful dietary intervention to reduce the burden of T2D [32, 110, 153, 161]. Notably, the mTORC1 activator milk exerts the opposite functions of the most commonly used anti-diabetic drug metformin [162], which activates AMPK, suppresses mTORC1, reduces plasma BCAA levels, and targets BCAAs to the adipose tissue $[163,164]$. Future studies should pay attention to the miRNA-29b content of milk and milk products and its impact on the regulation of BCAA plasma levels in relation to T2D prevalence.

Abbreviations: AMPK: 5'-adenosine monophosphate-activated protein kinase; BCAA: branchedchain amino acid; BCKA: branched-chain $\alpha$-keto acid; BCKD: branched-chain $\alpha$-keto acid dehydrogenase; BCKDK: BCKA dehydrogenase kinase; DBT: dihydrolipoamide branched-chain acyltransferase; DNMT1: DNA methyltransferase 1; GH: growth hormone; EGF: epidermal growth factor; EPIC: European Prospective Investigation into Cancer and Nutrition; ER: endoplasmic reticulum; EV: extracellular vesicle; FcRn: neonatal Fc receptor; GIP: glucosedependent insulinotropic peptide; GLP-1: glucagon-like polypeptide-1: HPFS: Health Professionals Follow-up Study; IGF-1: insulin-like growth factor-1; IR: insulin resistance; IRS-1: insulin receptor substrate 1; MAFA: V-MAF avian musculoaponeurotic fibrosarcoma oncogene homolog A; MAFB: V-MAF musculoaponeurotic fibrosarcoma oncogene family, protein $\mathrm{B}$; MFG: milk fat globule; mRNA: messenger ribonucleic acid; miRNA: micro-ribonucleic acid; MONICA: monitoring trends and determinants in cardiovascular diseases; mTORC1: mechanistic target of rapamycin complex 1; NHS: Nurses' Health Study; PI3K: phosphinositide-3 kinase; PTEN: phosphatase and tensin homolog; RCT: randomized controlled trial; Rheb: RAS-homolog enriched in brain; S6K1: ribosomal protein S6 kinase, 70-KD, 1; T2D: type 2 diabetes mellitus

Competing interests: The authors have no financial interests or conflicts of interest.

Authors' contribution: Both authors contributed equally to this study.

\section{REFERENCES}

1. Per capita consumption of milk United States, 2017 [https://www.statista.com/ statistics/448642/per-capita-comsumption-of-milk-in-the-us/.] Retrieved July 25, 2019

2. Hoyt G, Hickey MS, Cordain L: Dissociation of the glycaemic and insulinaemic responses to whole and skimmed milk. Br J Nutr. 2005, 93:175-7.

3. Liljeberg Elmstahl H, Bjorck I: Milk as a supplement to mixed meals may elevate postprandial insulinaemia. Eur J Clin Nutr. 2001, 55:994-9.

4. Guo J, Givens DI, Astrup A, Bakker SJL, Goossens GH, Kratz M, Marette A, et al.: The impact of dairy products in the development of type 2 diabetes: Where does the evidence stand in 2019? Adv Nutr. 2019, pii: nmz050. [Epub ahead of print].

5. Hoppe C, Molgaard C, Vaag A, Barkholt V, Michaelsen KF: High intakes of milk, but not meat, increase s-insulin and insulin resistance in 8-year-old boys. Eur J Clin Nutr. 2005, 59:393-8. 
6. Bergholdt HK, Nordestgaard BG, Ellervik C: Milk intake is not associated with low risk of diabetes or overweight-obesity: a Mendelian randomization study in 97,811 Danish individuals. Am J Clin Nutr. 2015, 102:487-96.

7. Song Y, Chavarro JE, Cao Y, Qiu W, Mucci L, Sesso HD, Stampfer MJ, et al.: Whole milk intake is associated with prostate cancer-specific mortality among U.S. male physicians. J Nutr. 2013, 143:189-96.

8. Sluijs I, Forouhi NG, Beulens JW, van der Schouw YT, Agnoli C, Arriola L, Balkau B, et al.: InterAct Consortium. The amount and type of dairy product intake and incident type 2 diabetes: results from the EPIC-InterAct Study. Am JClin Nutr. 2012, 96:382-90.

9. Brouwer-Brolsma EM, Sluik D, Singh-Povel CM, Feskens EJM: Dairy product consumption is associated with pre-diabetes and newly diagnosed type 2 diabetes in the Lifelines Cohort Study. Br J Nutr. 2018, 119:442-55.

10. Hruby A, Ma J, Rogers G, Meigs JB, Jacques PF: Associations of dairy intake with incident prediabetes or diabetes in middle-aged adults vary by both dairy type and glycemic status. J Nutr. 2017, 147:1764-75.

11. Millward DJ, Layman DK, Tomé D, Schaafsma G: Protein quality assessment: impact of expanding understanding of protein and amino acid needs for optimal health. Am J Clin Nutr. 2008, 87:1576S-81S.

12. Souci SW, Fachmann W, Kraut H: Die Zusammensetzung der Lebensmittel. 8. revidierte und ergänzte Auflage. 2016, 1263 S. Wissenschaftliche Verlagsgesellschaft Stuttgart (WVG).

13. Lenders CM, Liu S, Wilmore DW, Sampson L, Dougherty LW, Spiegelman D, Willett WC: Evaluation of a novel food composition database that includes glutamine and other amino acids derived from gene sequencing data. Eur J Clin Nutr. 2009, 63:1433-9.

14. Zheng Y, Li Y, Qi Q, Hruby A, Manson JE, Willett WC, Wolpin BM, et al.: Cumulative consumption of branched-chain amino acids and incidence of type 2 diabetes. Int $\mathbf{J}$ Epidemiol. 2016, 45:1482-92.

15. Yu R, Woo J, Chan R, Sham A, Ho S, Tso A, Cheung B, et al.: Relationship between dietary intake and the development of type 2 diabetes in a Chinese population: the Hong Kong Dietary Survey. Public Health Nutr. 2011, 14:1133-41.

16. Lindeberg S, Eliasson M, Lindahl B, Ahren B: Low serum insulin in traditional Pacific Islanders - the Kitava Study. Metabolism 1999, 48:1216-9.

17. Cordain L, Eades MR, Eades MD: Hyperinsulinemic diseases of civilization: more than just Syndrome X. Comp Biochem Physiol A Mol Integr Physiol. 2003, 136:95-112.

18. Lindeberg S. Paleolithic diets as a model for prevention and treatment of Western disease. Am J Hum Biol. 2012; 24:110-5.

19. Masharani U, Sherchan P, Schloetter M, Stratford S, Xiao A, Sebastian A, Nolte Kennedy M, et al.: Metabolic and physiologic effects from consuming a hunter-gatherer (Paleolithic)-type diet in type 2 diabetes. Eur J Clin Nutr. 2015, 69:944-8.

20. Fontes-Villalba M, Jonsson T, Granfeldt Y, Frassetto LA, Sundquist J, Sundquist K, Carrera-Bastos $\mathrm{P}$, et al.: A healthy diet with and without cereal grains and dairy products in patients with type 2 diabetes: study protocol for a random-order cross-over pilot study - Alimentation and Diabetes in Lanzarote-ADILAN. Trials 2014, 15:2.

21. Andre C, Cota D: Coupling nutrient sensing to metabolic homoeostasis: the role of the mammalian target of rapamycin complex 1 pathway. Proc Nutr Soc. 2012, 71:502-10. 
22. Rabanal-Ruiz Y, Korolchuk VI: mTORC1 and nutrient homeostasis: The central role of the lysosome. Int J Mol Sci. 2018, 19(3):pii: E818.

23. Saxton RA, Sabatini DM: mTOR signaling in growth, metabolism, and disease. Cell 2017, 168:960-76.

24. Um SH, D'Alessio D, Thomas G: Nutrient overload, insulin resistance, and ribosomal protein S6 kinase 1, S6K1. Cell Metab. 2006, 3:393-402.

25. Copps KD, White MF: Regulation of insulin sensitivity by serine/threonine phosphorylation of insulin receptor substrate proteins IRS1 and IRS2. Diabetologia. 2012, 55:2565-82.

26. Catalan V, Gomez-Ambrosi J, Rodriguez A, Ramirez B, Andrada P, Rotellar F, Valentí $\mathrm{V}$, et al.: Expression of S6K1 in human visceral adipose tissue is upregulated in obesity and related to insulin resistance and inflammation. Acta Diabetol. 2015, 52:257-66.

27. Jung SH, Jung CH, Reaven GM, Kim SH: Adapting to insulin resistance in obesity: role of insulin secretion and clearance. Diabetologia 2018, 61:681-7.

28. Rabanal-Ruiz Y, Otten EG, Korolchuk VI: mTORC1 as the main gateway to autophagy. Essays Biochem. 2017, 61:565-84.

29. Bartolome A, Garcia-Aguilar A, Asahara SI, Kido Y, Guillen C, Pajvani UB, Benito M: MTORC1 regulates both general autophagy and mitophagy induction after oxidative phosphorylation uncoupling. Mol Cell Biol. 2017, 37(23):pii: e00441-17.

30. Hur KY, Jung HS, Lee MS: Role of autophagy in $\beta$-cell function and mass. Diabetes Obes Metab. 2010, 12 Suppl 2:20-6.

31. Zoncu R, Efeyan A, Sabatini DM: mTOR: from growth signal integration to cancer, diabetes and ageing. Nat Rev Mol Cell Biol. 2011, 12:21-35.

32. Melnik BC: Leucine signaling in the pathogenesis of type 2 diabetes and obesity. World J Diabetes. 2012, 3:38-53.

33. Yoon MS: The emerging role of branched-chain amino acids in insulin resistance and metabolism. Nutrients. 2016, 8(7)pii: E405.

34. Arneth B, Arneth R, Shams M: Metabolomics of type 1 and type 2 diabetes. Int J Mol Sci. 2019, 20(10)pii: E2467.

35. Ardestani A, Lupse B, Kido Y, Leibowitz G, Maedler K: mTORC1 signaling: A doubleedged sword in diabetic $\beta$ cells. Cell Metab. 2018, 27:314-31.

36. Yuan T, Rafizadeh S, Gorrepati KD, Lupse B, Oberholzer J, Maedler K, Ardestani A: Reciprocal regulation of mTOR complexes in pancreatic islets from humans with type 2 diabetes. Diabetologia 2017, 60:668-78.

37. Ali M, Bukhari SA, Ali M, Lee HW: Upstream signalling of mTORC1 and its hyperactivation in type 2 diabetes (T2D). BMB Rep. 2017, 50:601-9.

38. Guillen $\mathrm{C}$, Benito $\mathrm{M}$ : mTORC1 overactivation as a key aging factor in the progression to type 2 diabetes mellitus. Front Endocrinol (Lausanne) 2018, 9:621.

39. Jaafar R, Tran S, Shah A, Sun G, Valdearcos M, Marchetti P, Masini M, et al.: mTORC1 to AMPK switching underlies $\beta$-cell metabolic plasticity during maturation and diabetes. J Clin Invest. 2019, 130:pii: 127021.

40. Melnik BC, John SM, Schmitz G: Milk is not just food but most likely a genetic transfection system activating mTORC1 signaling for postnatal growth. Nutr J. 2013, 12:103.

41. Melnik BC: Milk - a nutrient system of mammalian evolution promoting mTORC1dependent translation. Int J Mol Sci. 2015, 16:17048-87. 
42. Avruch J, Long X, Ortiz-Vega S, Rapley J, Papageorgiou A, Dai N: Amino acid regulation of TOR complex 1. Am J Physiol Endocrinol Metab. 2009, 296:E592-602.

43. Foster KG, Fingar DC: Mammalian target of rapamycin (mTOR): conducting the cellular signaling symphony. J Biol Chem. 2010, 285:14071-7.

44. Duran RV, Hall MN: Glutaminolysis feeds mTORC1. Cell Cycle. 2012, 11:4107-8.

45. Kim SG, Buel GR, Blenis J: Nutrient regulation of the mTOR complex 1 signaling pathway. Mol Cells. 2013, 35:463-73.

46. Jewell JL, Russell RC, Guan KL: Amino acid signalling upstream of mTOR. Nat Rev Mol Cell Biol. 2013, 14:133-9.

47. Ricoult SJ, Manning BD: The multifaceted role of mTORC1 in the control of lipid metabolism. EMBO Rep. 2013, 14:242-51.

48. Bar-Peled L, Sabatini DM: Regulation of mTORC1 by amino acids. Trends Cell Biol. 2014, 24:400-6.

49. Zheng X, Liang Y, He Q, Yao R, Bao W, Bao L, Wang Y, et al.: Current models of mammalian target of rapamycin complex 1 (mTORC1) activation by growth factors and amino acids. Int J Mol Sci. 2014, 15:20753-69.

50. Ostman EM, Liljeberg Elmstahl HG, Bjorck IM: Inconsistency between glycemic and insulinemic responses to regular and fermented milk products. Am J Clin Nutr. 2001, 74:96-100.

51. Power O, Hallihan A, Jakeman P: Human insulinotropic response to oral ingestion of native and hydrolysed whey protein. Amino Acids 2009, 37:333-9.

52. Boirie Y, Dangin M, Gachon P, Vasson MP, Maubois JL, Beaufrère B: Slow and fast dietary proteins differently modulate postprandial protein accretion. Proc Natl Acad Sci USA. 1997, 94:14930-5.

53. Yang J, Chi Y, Burkhardt BR, Guan Y, Wolf BA. Leucine metabolism in regulation of insulin secretion from pancreatic beta cells. Nutr Rev. 2010, 68:270-9.

54. Moore WT, Bowser SM, Fausnacht DW, Staley LL, Suh KS, Liu D: Beta cell function and the nutritional state: dietary factors that influence insulin secretion. Curr Diab Rep. 2015, 15:76.

55. Hoppe C, Molgaard C, Dalum C, Vaag A, Michaelsen KF: Differential effects of casein versus whey on fasting plasma levels of insulin, IGF-1 and IGF-1/IGFBP-3: results from a randomized 7-day supplementation study in prepubertal boys. Eur J Clin Nutr. 2009, 63:1076-83.

56. Frid AH, Nilsson M, Holst JJ, Bjorck IM: Effect of whey on blood glucose and insulin responses to composite breakfast and lunch meals in type 2 diabetic subjects. Am J Clin Nutr. 2005, 82:69-75.

57. Park YM, Heden TD, Liu Y, Nyhoff LM, Thyfault JP, Leidy HJ, Kanaley JA: A highprotein breakfast induces greater insulin and glucose-dependent insulinotropic peptide responses to a subsequent lunch meal in individuals with type 2 diabetes. J Nutr. 2015, 145:452-8.

58. Adams RL, Broughton KS: Insulinotropic effects of whey: mechanisms of action, recent clinical trials, and clinical applications. Ann Nutr Metab. 2016, 69:56-63.

59. Nielsen SD, Beverly RL, Qu Y, Dallas DC: Milk bioactive peptide database: A comprehensive database of milk protein-derived bioactive peptides and novel visualization. Food Chem. 2017, 232:673-82. 
60. Dibble CC, Cantley LC: Regulation of mTORC1 by PI3K signaling. Trends Cell Biol. 2015, 25:545-55.

61. Boland BB, Rhodes CJ, Grimsby JS: The dynamic plasticity of insulin production in $\beta$ cells. Mol Metab. 2017, 6:958-73.

62. Norat T, Dossus L, Rinaldi S, Overvad K, Gronbaek H, Tjonneland A, Olsen A, et al.: Diet, serum insulin-like growth factor-I and IGF-binding protein-3 in European women. Eur J Clin Nutr. 2007, 61:91-8.

63. Crowe FL, Key TJ, Allen NE, Appleby PN, Roddam A, Overvad K, Gronbaek H, et al.: The association between diet and serum concentrations of IGF-I, IGFBP-1, IGFBP-2, and IGFBP-3 in the European Prospective Investigation into Cancer and Nutrition. Cancer Epidemiol Biomarkers Prev. 2009, 18:1333-40.

64. Qin LQ, He K, Xu JY: Milk consumption and circulating insulin-like growth factor-I level: a systematic literature review. Int J Food Sci Nutr. 2009, 60 Suppl 7:330-40.

65. Rich-Edwards JW, Ganmaa D, Pollak MN, Nakamoto EK, Kleinman K, Tserendolgor U, Willett WC, et al.: Milk consumption and the prepubertal somatotropic axis. Nutr J. 2007, 6:28.

66. Harp JB, Goldstein S, Phillips LS: Nutrition and somatomedin. XXIII. Molecular regulation of IGF-I by amino acid availability in cultured hepatocytes. Diabetes 1991, 40:95-101.

67. Wheelhouse NM, Stubbs AK, Lomax MA, MacRae JC, Hazlerigg DG: Growth hormone and amino acid supply interact synergistically to control insulin-like growth factor-I production and gene expression in cultured ovine hepatocytes. J Endocrinol. 1999, 163:353-61.

68. Miller RA, Buehner G, Chang Y, Harper JM, Sigler R, Smith-Wheelock M: Methioninedeficient diet extends mouse lifespan, slows immune and lens aging, alters glucose, T4, IGF-I and insulin levels, and increases hepatocyte MIF levels and stress resistance. Aging Cell. 2005, 4:119-25.

69. Fleddermann M, Demmelmair H, Grote V, Bidlingmaier M, Grimminger P, Bielohuby M, Koletzko B: Role of selected amino acids on plasma IGF-I concentration in infants. Eur J Nutr. 2017, 56:613-20.

70. Rotwein P, Pollock KM, Didier DK, Krivi GG: Organization and sequence of the human insulin-like growth factor I gene. Alternative RNA processing produces two insulin-like growth factor I precursor peptides. J Biol Chem. 1986, 261:4828-32.

71. Fotsis T, Murphy C, Gannon F: Nucleotide sequence of the bovine insulin-like growth factor 1 (IGF-1) and its IGF-1A precursor. Nucleic Acids Res. 1990, 18:676.

72. Hoeflich A, Meyer Z: Functional analysis of the IGF-system in milk. Best Pract Res Clin Endocrinol Metab. 2017, 31:409-18.

73. Hoppe C, Molgaard C, Michaelsen KF: Cow's milk and linear growth in industrialized and developing countries. Annu Rev Nutr. 2006, 26:131-73.

74. Wiley AS: Dairy and milk consumption and child growth: Is BMI involved? An analysis of NHANES 1999-2004. Am J Hum Biol. 2010, 22:517-25.

75. Melnik BC, John SM, Schmitz G: Over-stimulation of insulin/IGF-1 signaling by western diet may promote diseases of civilization: lessons learnt from Laron syndrome. Nutr Metab (Lond). 2011, 8:41.

76. Guevara-Aguirre J, Procel P, Guevara C, Guevara-Aguirre M, Rosado V, Teran E: Despite higher body fat content, Ecuadorian subjects with Laron syndrome have less 
insulin resistance and lower incidence of diabetes than their relatives. Growth Horm IGF Res. 2016, 28:76-8.

77. Guevara-Aguirre J, Guevara A, Bahamonde M: Insulin resistance depends on GH counter-regulation in two syndromes of short stature. Growth Horm IGF Res. 2018, 38:44-8.

78. Rajpathak SN, He M, Sun Q, Kaplan RC, Muzumdar R, Rohan TE, Gunter MJ, et al.: Insulin-like growth factor axis and risk of type 2 diabetes in women. Diabetes. 2012, 61:2248-54.

79. Drogan D, Schulze MB, Boeing H, Pischon T: Insulin-like growth factor 1 and insulinlike growth factor-binding protein 3 in relation to the risk of type 2 diabetes mellitus: Results from the EPIC-Potsdam study. Am J Epidemiol. 2016, 183:553-60.

80. Zhu Y, Mendola P, Albert PS, Bao W, Hinkle SN, Tsai MY, Zhang C: Insulin-like growth factor axis and gestational diabetes mellitus: A longitudinal study in a multiracial cohort. Diabetes. 2016; 65:3495-504.

81. Nutrition during pregnancy. [https://www.acog.org/ /media/For\%20Patients/faq001.pdf.] Retrieved February, 2018

82. Melnik BC, John SM, Schmitz G: Milk consumption during pregnancy increases birth weight, a risk factor for the development of diseases of civilization. J Trans1 Med. 2015, 13:13.

83. Johnsson IW, Haglund B, Ahlsson F, Gustafsson J: A high birth weight is associated with increased risk of type 2 diabetes and obesity. Pediatr Obes. 2015, 10:77-83.

84. Yao Y, Jones E, Inoki K: Lysosomal regulation of mTORC1 by amino acids in mammalian cells. Biomolecules 2017, 7(3):pii: E51.

85. Stracka D, Jozefczuk S, Rudroff F, Sauer U, Hall MN: Nitrogen source activates TOR (target of rapamycin) complex 1 via glutamine and independently of Gtr/Rag proteins. J Biol Chem. 2014, 289:25010-20.

86. Jewell JL, Kim YC, Russell RC, Yu FX, Park HW, Plouffe SW, Tagliabracci VS, et al.: Metabolism. Differential regulation of mTORC1 by leucine and glutamine. Science 2015, 347:194-8.

87. Kim J, Kim E: Rag GTPase in amino acid signaling. Amino acids. 2016, 48:915-28.

88. Nguyen TP, Frank AR, Jewell JL: Amino acid and small GTPase regulation of mTORC1. Cell Logist. 2017, 7:e1378794.

89. Yasuda M, Tanaka Y, Kume S, Morita Y, Chin-Kanasaki M, Araki H, Isshiki K, et al.: Fatty acids are novel nutrient factors to regulate mTORC1 lysosomal localization and apoptosis in podocytes. Biochim Biophys Acta. 2014, 1842:1097-108.

90. Kumar S, Tikoo K: Independent role of PP2A and mTORc1 in palmitate induced podocyte death. Biochimie. 2015, 112:73-84.

91. Li H, Xu W, Ma Y, Zhou S, Xiao R: Milk fat globule membrane protein promotes $\mathrm{C} 2 \mathrm{C} 12$ cell proliferation through the PI3K/Akt signaling pathway. Int J Biol Macromol. 2018, 114:1305-14.

92. Zempleni J, Baier SR, Howard KM, Cui J: Gene regulation by dietary microRNAs. Can J Physiol Pharmacol. 2015, 93:1097-102.

93. Benmoussa A, Lee CH, Laffont B, Savard P, Laugier J, Boilard E, Gilbert C, et al.: Commercial dairy cow milk microRNAs resist digestion under simulated gastrointestinal tract conditions. J Nutr. 2016, 146:2206-15. 
94. Melnik BC, Kakulas F, Geddes DT, Hartmann PE, John SM, Carrera-Bastos P, Cordain L, et al.: Milk miRNAs: simple nutrients or systemic functional regulators? Nutr Metab (Lond). 2016, 13:42.

95. Melnik BC, Schmitz G: MicroRNAs: milk's epigenetic regulators. Best Pract Res Clin Endocrinol Metab. 2017, 31:427-42.

96. Melnik BC, Schmitz G: Milk's role as an epigenetic regulator in health and disease. Diseases. 2017, 5(1):pii: E12.

97. Benmoussa A, Ly S, Shan ST, Laugier J, Boilard E, Gilbert C, Provost P: A subset of extracellular vesicles carries the bulk of microRNAs in commercial dairy cow's milk. J Extracell Vesicles. 2017, 6:1401897.

98. Zempleni J, Sukreet S, Zhou F, Wu D, Mutai E: Milk-derived exosomes and metabolic regulation. Annu Rev Anim Biosci. 2019, 7:245-62.

99. Benmoussa A, Provost P: Milk microRNAs in health and disease. Compr Rev Food Sci Food Safety, 2019.

100. Manca S, Upadhyaya B, Mutai E, Desaulniers AT, Cederberg RA, White BR, Zempleni J: Milk exosomes are bioavailable and distinct microRNA cargos have unique tissue distribution patterns. Sci Rep. 2018, 8:11321.

101. Betker JL, Angle BM, Graner MW, Anchordoquy TJ: The potential of exosomes from cow milk for oral delivery. J Pharm Sci. 2019, 108:1496-505.

102. Ambros V: The functions of animal microRNAs. Nature 2004, 431:350-5.

103. Bushati N, Cohen SM: microRNA functions. Annu Rev Cell Dev Biol. 2007, 23:175205.

104. Golan-Gerstl R, Elbaum Shiff Y, Moshayoff V, Schecter D, Leshkowitz D, Reif S: Characterization and biological function of milk-derived miRNAs. Mol Nutr Food Res. 2017, 61(10).

105. Kirchner B, Pfaffl MW, Dumpler J, von Mutius E, Ege MJ: microRNA in native and processed cow's milk and its implication for the farm milk effect on asthma. J Allergy Clin Immunol. 2016, 137:1893-95.e13.

106. Pan W, Zhu S, Yuan M, Cui H, Wang L, Luo X, Li J, et al.: MicroRNA-21 and microRNA-148a contribute to DNA hypomethylation in lupus CD4+ T cells by directly and indirectly targeting DNA methyltransferase 1. J Immunol. 2010, 184:6773-81.

107. Zhu A, Xia J, Zuo J, Jin S, Zhou H, Yao L, Huang H, et al.: MicroRNA-148a is silenced by hypermethylation and interacts with DNA methyltransferase 1 in gastric cancer. Med Oncol. 2012, 29:2701-9.

108. Melnik BC: Milk disrupts p53 and DNMT1, the guardians of the genome: implications for acne vulgaris and prostate cancer. Nutr Metab (Lond). 2017, 14:55.

109. Melnik BC, Schmitz G: DNA methyltransferase 1-targeting miRNA-148a of dairy milk: a potential bioactive modifier of the human epigenome. Funct Food Health Disease. 2017, 7:671-87.

110. Melnik BC, Schmitz G: Exosomes of pasteurized milk: potential pathogens of Western diseases. J Transl Med. 2019, 17:3.

111. Qin H, Zhu X, Liang J, Wu J, Yang Y, Wang S, Shi W, et al.: MicroRNA-29b contributes to DNA hypomethylation of CD4+ T cells in systemic lupus erythematosus by indirectly targeting DNA methyltransferase 1. J Dermatol Sci. 2013, 69:61. 
112. Ouni M, Gunes Y, Belot MP, Castell AL, Fradin D, Bougnères P: The IGF1 P2 promoter is an epigenetic QTL for circulating IGF1 and human growth. Clin Epigenetics. 2015, $7: 22$.

113. Kuroda A, Rauch TA, Todorov I, Ku HT, Al-Abdullah IH, Kandeel F, Mullen Y, et al.: Insulin gene expression is regulated by DNA methylation. PLoS One 2009, 4:e6953.

114. Chen J, Ying Y, Zhu H, Zhu T, Qu C, Jiang J, Fang B: Curcumin-induced promoter hypermethylation of the mammalian target of rapamycin gene in multiple myeloma cells. Oncol. Lett. 2019, 17:1108-14.

115. Buscaglia LE, Li Y: Apoptosis and the target genes of microRNA-21. Chin. J. Cancer 2011, 30:371-80.

116. Dey N, Das F, Ghosh-Choudhury N, Mandal CC, Parekh DJ, Block K, Kasinath BS, et al.: microRNA-21 governs TORC1 activation in renal cancer cell proliferation and invasion. PLoS One. 2012, 7:e37366.

117. Baddela VS, Nayan V, Rani P, Onteru SK, Singh D: Physicochemical biomolecular insights into buffalo milk-derived nanovesicles. Appl Biochem Biotechnol. 2016, 178:544-57.

118. Le MT, Shyh-Chang N, Khaw SL, Chin L, Teh C, Tay J, O'Day E, et al.: Conserved regulation of 553 network dosage by microRNA-125b occurs through evolving miRNAtarget gene pairs. PLoS Genet. 2011, 7:e1002242.

119. Gao HN, Guo HY, Zhang H, Xie XL, Wen PC, Ren FZ: Yak-milk-derived exosomes promote proliferation of intestinal epithelial cells in a hypoxic environment. J Dairy Sci. 2019, 102:985-96.

120. Feng Z, Levine AJ: The regulation of energy metabolism and the IGF-1/mTOR pathways by the p53 protein. Trends Cell Biol. 2010, 20:427-34.

121. Feng Z: p53 regulation of the IGF-1/AKT/mTOR pathways and the endosomal compartment. Cold Spring Harb Perspect Biol. 2010, 2:a001057.

122. Budanov AV, Karin M: p53 target genes sestrin1 and sestrin2 connect genotoxic stress and mTOR signaling. Cell. 2008, 134:451-60.

123. Alejandro EU, Bozadjieva N, Blandino-Rosano M, Wasan MA, Elghazi L, Vadrevu S, Satin L, et al.: Overexpression of kinase-Dead mTOR impairs glucose homeostasis by regulating insulin secretion and not beta-cell mass. Diabetes. 2017, 66:2150-62.

124. Elghazi L, Blandino-Rosano M, Alejandro E, Cras-Meneur C, Bernal-Mizrachi E: Role of nutrients and mTOR signaling in the regulation of pancreatic progenitors development. Mol Metab. 2017, 6:560-73.

125. Artner I, Hang Y, Mazur M, Yamamoto T, Guo M, Lindner J, Magnuson MA, et al.: MafA and MafB regulate genes critical to beta-cells in a unique temporal manner. Diabetes. 2010, 59:2530-9.

126. Hang Y, Stein R: MafA and MafB activity in pancreatic $\beta$ cells. Trends Endocrinol Metab. 2011, 22:364-73.

127. Cheng P, Chen C, He HB, Hu R, Zhou HD, Xie H, Zhu W, et al.: miR-148a regulates osteoclastogenesis by targeting $\mathrm{V}$-maf musculoaponeurotic fibrosarcoma oncogene homolog B. J Bone Miner Res. 2013, 28:1180-90.

128. Munch EM, Harris RA, Mohammad M, Benham AL, Pejerrey SM, Showalter L, Hu M, et al.: Transcriptome profiling of microRNA by Next-Gen deep sequencing reveals known and novel miRNA species in the lipid fraction of human breast milk. PLoS One 2013, 8:e50564. 
129. Felig P, Marliss E, Cahill GFJ Jr: Plasma amino acid levels and insulin secretion in obesity. N Engl J Med. 1969, 281:811-6.

130. Newgard CB, An J, Bain JR, Muehlbauer MJ, Stevens RD, Lien LF, Haqq AM, et al.: A branched-chain amino acid-related metabolic signature that differentiates obese and lean humans and contributes to insulin resistance. Cell Metab. 2009, 9:311-26.

131. Lynch CJ, Adams SH: Branched-chain amino acids in metabolic signalling and insulin resistance. Nat Rev Endocrinol. 2014, 10:723-36.

132. Lu J, Xie G, Jia W, Jia W: Insulin resistance and the metabolism of branched-chain amino acids. Front Med. 2013, 7:53-9.

133. She P, Olson KC, Kadota Y, Inukai A, Shimomura Y, Hoppel CL, Adams SH, et al.: Leucine and protein metabolism in obese Zucker rats. PLoS One 2013, 8:e59443.

134. Menni C, Fauman E, Erte I, Perry JR, Kastenmüller G, Shin SY, Petersen AK, et al.: Biomarkers for type 2 diabetes and impaired fasting glucose using a nontargeted metabolomics approach. Diabetes. 2013, 62: 4270-6.

135. Lu Y, Wang Y, Ong CN, Subramaniam T, Choi HW, Yuan JM, Koh WP, et al.: Metabolic signatures and risk of type 2 diabetes in a Chinese population: an untargeted metabolomics study using both LC-MS and GC-MS. Diabetologia. 2016, 59:2349-59.

136. Chen T, Ni Y, Ma X, Liu J, Huang F, Hu C, Xie G, et al.: Branched-chain and aromatic amino acid profiles and diabetes risk in Chinese populations. Sci Rep. 2016, 6:20594.

137. White PJ, Lapworth AL, An J, Wang L, McGarrah RW, Stevens RD, Ilkayeva O, et al.: Branched-chain amino acid restriction in Zucker-fatty rats improves muscle insulin sensitivity by enhancing efficiency of fatty acid oxidation and acyl-glycine export. Mol Metab. 2016, 5:538-51.

138. Lotta LA, Scott RA, Sharp SJ, Burgess S, Luan J, Tillin T, Schmidt AF, et al.: Genetic predisposition to an impaired metabolism of the branched-chain amino acids and risk of type 2 diabetes: A Mendelian randomisation analysis. PLoS Med. 2016, 13:e1002179.

139. Zhou M, Jing S, Wu CY, Shu L, Dong W, Liu Y, Chen M, et al.: Targeting BCAA catabolism to treat obesity-associated insulin resistance. Diabetes. 2019, 68:1730-46.

140. Hung YH, Kanke M, Kurtz CL, Cubitt R, Bunaciu RP, Miao J, Zhou L, et al.: Acute suppression of insulin resistance-associated hepatic miR-29 in vivo improves glycemic control in adult mice. Physiol Genomics. 2019, 51:379-89.

141. Kurtz CL, Peck BC, Fannin EE, Beysen C, Miao J, Landstreet SR, Ding S, et al.: MicroRNA-29 fine-tunes the expression of key FOXA2-activated lipid metabolism genes and is dysregulated in animal models of insulin resistance and diabetes. Diabetes. 2014, 63:3141-8.

142. He A, Zhu L, Gupta N, Chang Y, Fang F: Overexpression of micro ribonucleic acid 29, highly up-regulated in diabetic rats, leads to insulin resistance in 3T3-L1 adipocytes. Mol Endocrinol. 2007, 21:2785-94.

143. Roggli E, Gattesco S, Caille D, Briet C, Boitard C, Meda P, Regazzi R: Changes in microRNA expression contribute to pancreatic $\beta$-cell dysfunction in prediabetic NOD mice. Diabetes. 2012, 61:1742-51.

144. Pullen TJ, da Silva Xavier G, Kelsey G, Rutter GA: miR-29a and miR-29b contribute to pancreatic beta-cell-specific silencing of monocarboxylate transporter 1 (Mct1). Mol Cell Biol. 2011, 31:3182-94.

145. Dooley J, Garcia-Perez JE, Sreenivasan J, Schlenner SM, Vangoitsenhoven R, Papadopoulou AS, Tian L, et al.: The microRNA-29 family dictates the balance between 
homeostatic and pathological glucose handling in diabetes and obesity. Diabetes. 2016, 65:53-61.

146. Baran-Gale J, Fannin EE, Kurtz CL, Sethupathy P: Beta cell 5'-shifted isomiRs are candidate regulatory hubs in type 2 diabetes. PLoS One 2013, 8:e73240.

147. Howard KM, Jati Kusuma R, Baier SR, Friemel T, Markham L, Vanamala J, Zempleni $\mathrm{J}$ : Loss of miRNAs during processing and storage of cow's (Bos taurus) milk. J Agric Food Chem. 2015, 63:588-92.

148. Baier SR, Nguyen C, Xie F, Wood JR, Zempleni J: MicroRNAs are absorbed in biologically meaningful amounts from nutritionally relevant doses of cow milk and affect gene expression in peripheral blood mononuclear cells, HEK-293 kidney cell cultures, and mouse livers. J Nutr. 2014, 144:1495-500.

149. Betker JL, Angle BM, Graner MW, Anchordoquy TJ: The potential of exosomes from cow milk for oral delivery. J Pharm Sci. 2019, 108:1496-505.

150. Li T, Balthasar JP: FcRn Expression in wildtype mice, transgenic mice, and in human tissues. Biomolecules. 2018, 8. pii: E115.

151. Mersey BD, Jin P, Danner DJ: Human microRNA (miR29b) expression controls the amount of branched chain alpha-ketoacid dehydrogenase complex in a cell. Hum Mol Genet. 2005, 14:3371-7.

152. Neinast M, Murashige D, Arany Z: Branched chain amino acids. Annu Rev Physiol. 2019, 81:139-64.

153. Melnik BC: The pathogenic role of persistent milk signaling in mTORC1- and milkmicroRNA-driven type 2 diabetes mellitus. Curr Diabetes Rev. 2015, 11:46-62.

154. Melnik BC, Schmitz G: Milk consumption does not prevent but induces type 2 diabetes. Diabetes Metab Res Rev. 2019 Jun 29, e3200. [Epub ahead of print].

155. Yu S, Zhao Z, Sun L, Li P: Fermentation results in quantitative changes in milk-derived exosomes and different effects on cell growth and survival. J Agric Food Chem. 2017, 65:1220-8.

156. Krokowski D, Han J, Saikia M, Majumder M, Yuan CL, Guan BJ, Bevilacqua E, et al.: A self-defeating anabolic program leads to $\beta$-cell apoptosis in endoplasmic reticulum stress-induced diabetes via regulation of amino acid flux. J Biol Chem. 2013, 288:17202-13.

157. Van Nielen M, Feskens EJ, Mensink M, Sluijs I, Molina E, Amiano P, Ardanaz E, et al.: InterAct Consortium. Dietary protein intake and incidence of type 2 diabetes in Europe: the EPIC-InterAct Case-Cohort Study. Diabetes Care. 2014, 37:1854-62.

158. Maida A, Chan JSK, Sjoberg KA, Zota A, Schmoll D, Kiens B, Herzig S, et al.: Repletion of branched chain amino acids reverses mTORC1 signaling but not improved metabolism during dietary protein dilution. Mol Metab. 2017, 6:873-81.

159. Cummings NE, Williams EM, Kasza I, Konon EN, Schaid MD, Schmidt BA, Poudel C, et al.: Restoration of metabolic health by decreased consumption of branched-chain amino acids. J Physiol. 2018, 596:623-45.

160. Solon-Biet SM, Cogger VC, Pulpitel T, Wahl D, Clark X, Bagley EE, Gregoriou GC, et al.: Branched-chain amino acids impact health and lifespan indirectly via amino acid balance and appetite control. Nature Metab. 2019, 1:532-45.

161. Canada's Food Guide. [https://food-guide.canada.ca/en/.] Retrieved October 11, 2019

162. Melnik BC, Schmitz G: Metformin: an inhibitor of mTORC1 signaling. J Endocrinol Diabetes Obes. 2014, 2:1029. 
163. Zemdegs J, Martin H, Pintana H, Bullich S, Manta S, Marques MA, Moro C, et al.: Metformin promotes anxiolytic and antidepressant-like responses in insulin-resistant mice by decreasing circulating branched-chain amino acids. J Neurosci. 2019, 39:593548.

164. Riera-Borrull M, Garcia-Heredia A, Fernandez-Arroyo S, Hernandez-Aguilera A, Cabre N, Cuyas E, Luciano-Mateo F, et al:: Metformin potentiates the benefits of dietary restraint: A metabolomic study. Int J Mol Sci. 2017, 18:pii: E2263. 